\title{
The Relationship between Primary and Secondary Recrystallization Texture of Grain Oriented Silicon Steel
}

\author{
Tomoji KUMANO, Tsutomu HARATANI and Yoshiyuki USHIGAMI ${ }^{1)}$ \\ Yawata R\&D Lab., Nippon Steel Corp., Tobihata-cho Tobata-ku Kitakyushu 804-8501 Japan. \\ 1) Electromagnetic Materials, Steel Research Lab., Nippon Steel Corp., 1 Shintomi Futtsu Chiba $293-8511$ Japan.
}

( Received on November 28, 2001; accepted in final form on January 16, 2002)

\begin{abstract}
The relationship between primary and secondary recrystallization texture of grain oriented silicon steel, of which process is the only one case applying the secondary recrystallization phenomenon in the steel industry, was examined. The specimens with various kinds of the primary texture were obtained by changing the cold rolling reduction and carbon content, and were secondary-recrystallized by injected inhibitor method. It was reconfirmed that in order to realize the sharp Goss orientation $(\{110\}\langle 001\rangle)$, the intensity of $\Sigma 9$ coincidence boundaries for Goss orientation will be strong and $\Sigma 9$ coincidence boundaries will move faster than $\Sigma 5$ boundaries.
\end{abstract}

KEY WORDS: electrical steel; silicon steel; grain boundary; texture; physical property.

\section{Introduction}

Grain Oriented Silicon Steel (GO) is mainly used for the core materials of transformer, and it is the only one product, which is being manufactured by applying the secondary recrystallization phenomenon in the field of steel industry. The most successful texture control has been achieved in the industrial scale. ${ }^{1)}$ Its magnetic properties, low core loss and high permeability along the rolling direction, are closely related to the secondary recrystallization texture, i.e., the sharpness of $\{110\}\langle 001\rangle$ (Goss texture). Therefore, to enhance the sharpness of Goss texture is essential, and it is no exaggeration to say that its history has been to find out the technology to improve the sharp Goss texture and to develop its easier manufacturing processes. ${ }^{2)}$

In 1934, the principal process was invented by Goss, ${ }^{3)}$ and was industrialized and developed by Armco (CGO: conventional grain oriented silicon steel). ${ }^{4,5)}$ The average deviation angle of $\langle 001\rangle$ axis from the rolling direction is around 7 degrees. In the1960's, high permeability grain oriented electrical steel (its average of the deviation is around 3 degrees $)^{4)}$ was developed by Nippon Steel ${ }^{6-9)}$ (HI-B: high permeability grain oriented silicon steel). Later in the 1970's Kawasaki Steel developed the similar grade. ${ }^{10,11)}$ The major differences among these three processes are the kind of the precipitates (inhibitor substances such as $\mathrm{MnS}$, $\mathrm{AlN}$ and $\mathrm{MnSe}$ ) and cold rolling condition (final coldrolling reduction) for primary recrystallization texture. However the technology for the preparation of inhibitors is the same, i.e., in order to obtain the finely-dispersed inhibitor, the temperature of slab re-heating at hot-rolling should be higher than their solution temperatures.

Recently, another technology for the preparation of in- hibitor (i.e., nitrogen injection technology) was developed by Nippon Steel. ${ }^{2,12-13)}$ In this method, as three major factors (inhibitor, structure and texture) of secondary recrystallization for grain oriented silicon steel can be given separately, many studies in the field of this technology have been carried out and its secondary recrystallization mechanism steel has been clarified. ${ }^{14-17)}$

The manufacturing process by using the former technology for the preparation of precipitates is named "the inherent inhibitor method" and the latter is named "the acquired inhibitor method" respectively. ${ }^{2)}$

Arai et al. ${ }^{16)}$ investigated the relationship between the primary and secondary (recrystallization) textures by changing the cold-rolling reduction. However in their study, as the final thicknesses of steel sheets were different, secondary textures might have been affected by inhibitor drop behavior, and this relationship has not been clarified perfectly yet.

In this study, in order to avoid the influence of inhibitor due to the thickness difference, specimens were prepared to have the same final thickness and their primary textures were prepared by changing the cold rolling reduction and the carbon content, and the relationships between primary and secondary texture were investigated under the same inhibitor and structure conditions.

\section{Experimental Procedure}

The chemical compositions of the specimens were $\mathrm{Si}$ : 3.25, C: 0.017(A), 0.056(B), Mn: 0.09, Al: 0.027, N: 0.008, $\mathrm{S}$ : $0.007 \mathrm{mass} \%$, as shown in Table 1. Experimental procedure for secondary recrystallization was as follows; Ingots were reheated at $1423 \mathrm{~K}$ and were hot-rolled to the thick- 
Table 1. Chemical compositions (mass\%)

\begin{tabular}{|c|c|c|}
\hline \multirow[t]{2}{*}{ Element } & \multicolumn{2}{|c|}{ Materials } \\
\hline & A & B \\
\hline $\mathrm{Si}$ & \multicolumn{2}{|c|}{ 3. 25} \\
\hline C & 0.017 & 0.056 \\
\hline $\mathrm{Mn}$ & \multicolumn{2}{|c|}{0.09} \\
\hline $\mathrm{Al}$ & \multicolumn{2}{|c|}{0.027} \\
\hline$N$ & \multicolumn{2}{|c|}{0.008} \\
\hline S & \multicolumn{2}{|c|}{0.007} \\
\hline
\end{tabular}

ness of 1.8, 2.2, 2.7 and $3.85(4.05) \mathrm{mm}$ in the laboratory. The reduction of last two passes of hot-rolling were controlled such as 20 and $15 \%$ in order to secure same texture after hot rolling.

These specimens were annealed at $1393 \mathrm{~K}$ in an atmosphere of $100 \% \mathrm{~N}_{2}$. The specimens were cold-rolled to the same thickness of $0.335 \mathrm{~mm}$ with the reductions of 81.4 , $84.8,87.6$ and $91.3(91.7) \%$, respectively. Following the cold-rolling, the specimens were annealed in a wet atmosphere of $25 \% \mathrm{~N}_{2}$ and $75 \% \mathrm{H}_{2}$ for decarburization and primary recrystallization. The annealing temperatures were $1103,1113,1123$ and $1133 \mathrm{~K}$. The specimen of the highest magnetic flux density (B8 (T) in an applied field of 800 $\mathrm{A} / \mathrm{m}$ ) at the specific annealing temperature was examined. Nitrogen was injected up to around 0.020 mass $\% \mathrm{~N}_{2}$ and the annealing separator, that mainly consists of $\mathrm{MgO}$, was coated on the specimen surfaces. The secondary recrystallization annealing was carried out under a $25 \% \mathrm{~N}_{2}$ and $75 \% \mathrm{H}_{2}$ atmosphere with the heating rate of $15 \mathrm{~K} / \mathrm{h}$ up to $1473 \mathrm{~K}$ and keeping for $20 \mathrm{~h}$ at $1473 \mathrm{~K}$ under a $100 \% \mathrm{H}_{2}$ atmosphere for purification.

B8-values were measured by the Single Sheet Tester (60 $\mathrm{mm}$ width, $300 \mathrm{~mm}$ length). The textures of primary and secondary recrystallized specimens were measured by $\mathrm{X}$ ray diffraction method. The primary recrystallization textures at the surface (1/5th thickness) and central positions of the specimens were obtained by the complete $\{100\}$ pole figures, and analyzed by the three-dimensional texture analysis by Vector method. ${ }^{18)}$ The secondary textures were measured by back-reflection Laue diffraction method.

The intensity of any coincidence orientation, $\Sigma i$, for a nucleus orientation $\mathrm{N}$ is expressed as $I c \Sigma i{ }^{19)}$ The intensities of $\Sigma 9$ and $\Sigma 5$ coincidence orientation to Goss $(\{110\}\langle 001\rangle)$

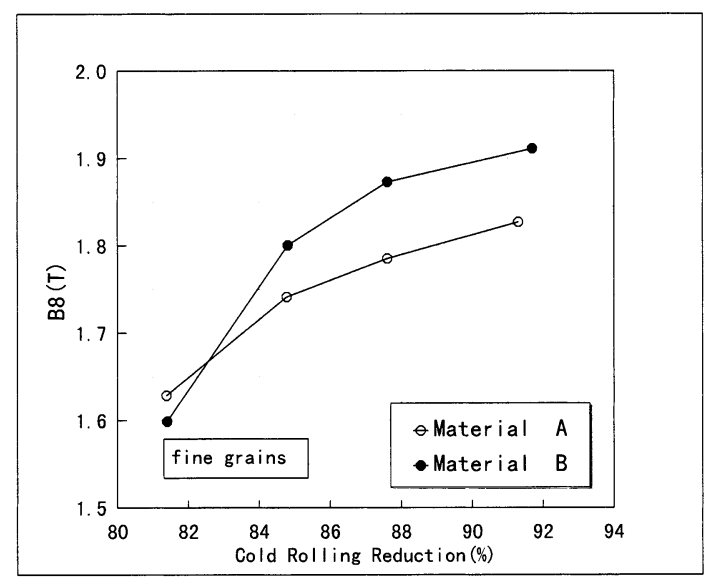

(a) Cold rolling reduction and $\mathrm{B} 8$ and dispersed Goss $(\{661\}\langle 126\rangle)$ orientation of primary textures, $I c \Sigma 9$ and $I c \Sigma 5$, were calculated.

\section{Result and Discussion}

\subsection{Magnetic Properties and Secondary Recrystal- lization Textures}

Figure 1(a) shows the relation between cold-rolling reduction and magnetic flux density (B8). In case of grain oriented silicon steel, B8-value corresponds to the sharpness of Goss texture. Unfortunately the specimen at cold rolling reduction $81.4 \%$ of material $\mathrm{B}$ had fine grains, i.e., poor secondary recrystallization. Material B has high B8 at the highest cold rolling reduction $(91.7 \%)$. But material A does not have so high B8-value even at the highest cold reduction $(91.3 \%)$.

Figure 2 shows textures of secondary recrystallized grains obtained by back-reflection Laue diffraction. The feature seems to be the same as B8, i.e., in case of the lower cold-reduction, the specimen has large dispersion from Goss orientation. Main orientation of dispersed grains is near $\{110\}\langle 227\rangle$ (more accurately $\{661\}\langle 126\rangle$ ). This orientation is rotated by $22.5^{\circ}$ from Goss around the normal direction axis .

Figure 3 shows the secondary recrystallization microstructures having peculiar features.

Table 2 shows the size classification of secondary recrystallized grains.

Figure 4 shows the secondary textures for each grain size classification. Smaller grains have larger deviation from Goss and correspond to lower B8. ${ }^{20)}$ On the other hand, large grains are sharp Goss texture.

Three misorientation angles $(\alpha, \beta$, and $\gamma)$ with respect to ND (Normal direction), RD (Rolling direction) and TD

Table 2. Size classification of secondary recrystallized grains.

\begin{tabular}{|c|c|c|c|c|c|}
\hline & & \multicolumn{4}{|c|}{ Rolling direction (mm) } \\
\hline & & $\leqq 5$ & $\leqq 10$ & $\leqq 20$ & $>20$ \\
\hline \multirow{4}{*}{$\begin{array}{c}\text { Transverse } \\
\text { direction } \\
(\mathrm{mm})\end{array}$} & $\leqq 5$ & (1) & & \multirow[b]{3}{*}{ (3) } & \multirow[b]{4}{*}{ (4) } \\
\hline & $\leqq 10$ & & (2) & & \\
\hline & $\leqq 20$ & & & & \\
\hline & $>20$ & & & & \\
\hline
\end{tabular}

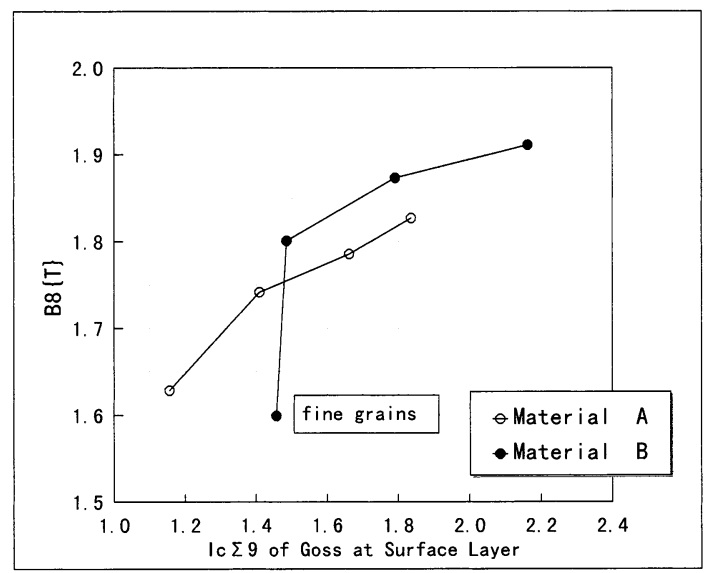

(b) Ic $\sum 9$ at surface layer and B8

Fig. 1. Relation among $\mathrm{B} 8(\mathrm{~T})$ and cold rolling reduction or $I c \Sigma 9$.

(a) Cold rolling reduction and B8. (b) Ic $\Sigma 9$ at surface layer and B8. 
(Transverse direction) from Goss texture are defined as follows; ND $(\alpha)$ is the angle formed by the longitudinal direc-

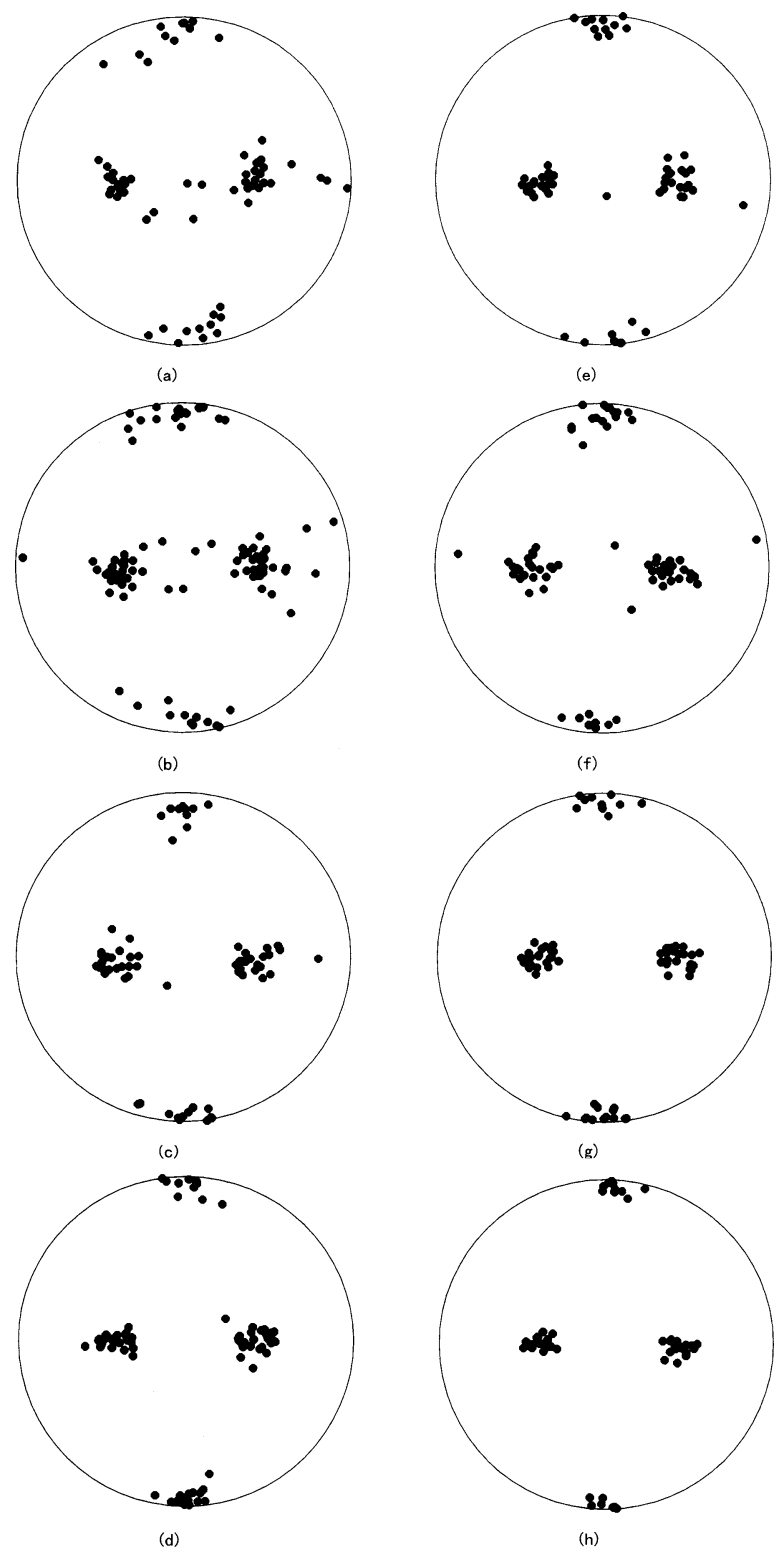

Fig. 2. $\{100\}$ pole figures representing secondary recrystallized grains.

(a), (b), (c) and (d): Material A with cold rolling reductions of $81.4,84.8,87.6$ and $91.3 \%$.

(e), (f), (g) and (h): Material B with cold rolling reductions of $81.4,84.8,87.6$, and $91.7 \%$.
Table 3. Average misorientation angles of secondary grains form exact Goss orientation $(\{110\}\langle 001\rangle)$ for each grain size.

\begin{tabular}{|c|c|c|c|c|c|}
\hline \multirow{3}{*}{ Material } & \multicolumn{2}{|c|}{ Size classification } & \multicolumn{3}{c|}{ Axis of Rotation } \\
\cline { 2 - 6 } & & Table 2 & ND $(\alpha)$ & $T D(\beta)$ & RD $(\gamma)$ \\
\hline \multirow{4}{*}{$A$} & $D \leqq 5 \mathrm{~mm}$ & $(1)$ & $21.3^{\circ}$ & $7.1^{\circ}$ & $11.9^{\circ}$ \\
\cline { 2 - 6 } & $5<D \leqq 10 \mathrm{~mm}$ & $(2)$ & 7.3 & 4.5 & 8.4 \\
\cline { 2 - 6 } & $10<D \leqq 20 \mathrm{~mm}$ & $(3)$ & 4.9 & 2.3 & 5.6 \\
\cline { 2 - 6 } & $20 \mathrm{~mm}<D$ & $(4)$ & 1.1 & 2.8 & 4.3 \\
\hline \multirow{3}{*}{$B$} & $D \leqq 5 \mathrm{~mm}$ & $(1)$ & 13.3 & 3.7 & 9.5 \\
\cline { 2 - 6 } & $5<D \leqq 10 \mathrm{~mm}$ & $(2)$ & 5.1 & 3.7 & 6.2 \\
\cline { 2 - 6 } & $10<D \leqq 20 \mathrm{~mm}$ & $(3)$ & 4.3 & 2.7 & 5.6 \\
\cline { 2 - 6 } & $20 \mathrm{~mm}<D$ & $(4)$ & 2.8 & 2.4 & 2.8 \\
\hline
\end{tabular}

tion and the projection of the [001] on specimen surface, $\operatorname{TD}(\beta)$ is the angle of rotation of the specimen about the [001] from the equiangular position and $\operatorname{RD}(\gamma)$ is the tilt angle of the [001] out of specimen surface, respectively. ${ }^{20)}$ Table 3 shows the averages of these misorientation angles $(\alpha, \beta$, and $\gamma)$. Even if grain size classification is the same, misorientaion angle is different, i.e., material A has larger misorientaion angle than material B. Especially, in case of smallest grain size (1) as shown in Table 2, the average misorientaion angles $(\alpha$ and $\beta$ ) from Goss of material $\mathrm{A}$ are rather large and its texture is almost $\{110\}\langle 227\rangle$. This will be the reason why $\mathrm{B} 8$ between material $\mathrm{A}$ and $\mathrm{B}$ are different. This is very important and to be discussed later.

\subsection{Primary Recrystallization Textures and Intensities of Coincidence Grains}

Many investigations ${ }^{14-17,19)}$ on the relationship between the primary and secondary recrystallization texture, especially, the sharpness of secondary recrystallization Goss and its intensity of coincidence boundaries in the primary texture, have been carried out. By applying vector method analysis, Harase et al. have proposed that Goss or cube secondary recrystallization evolve by higher frequencies coming in contact with mobile boundaries of these orientations in the cause of grain growth, and that these mobile boundaries are $\Sigma 9$ (Goss texture) or $\Sigma 7$ (cube texture). ${ }^{19)}$ Furthermore, they have concluded that the conditions for a viable nucleus of secondary recrystallization in a primary recrystallized stage, the orientation $\mathrm{N}$ should satisfy, are as follows; ${ }^{21)}$

(a) $P_{\mathrm{CN}} \Sigma 1$ (the product of $I_{\mathrm{N}}$ (the intensity of nucleus orientation $\mathrm{N}$ ) and $I c \Sigma 1$ (intensity of $\Sigma 1$ coincidence ori-

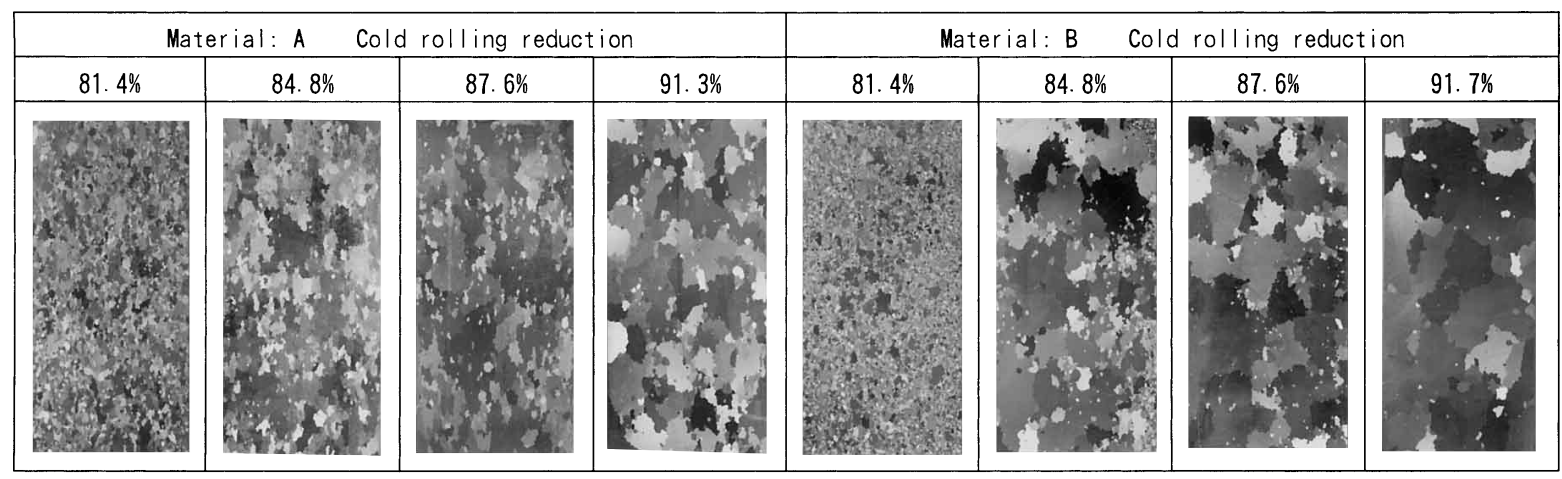

Fig. 3. Microstructure of secondary recrystallized grains. 


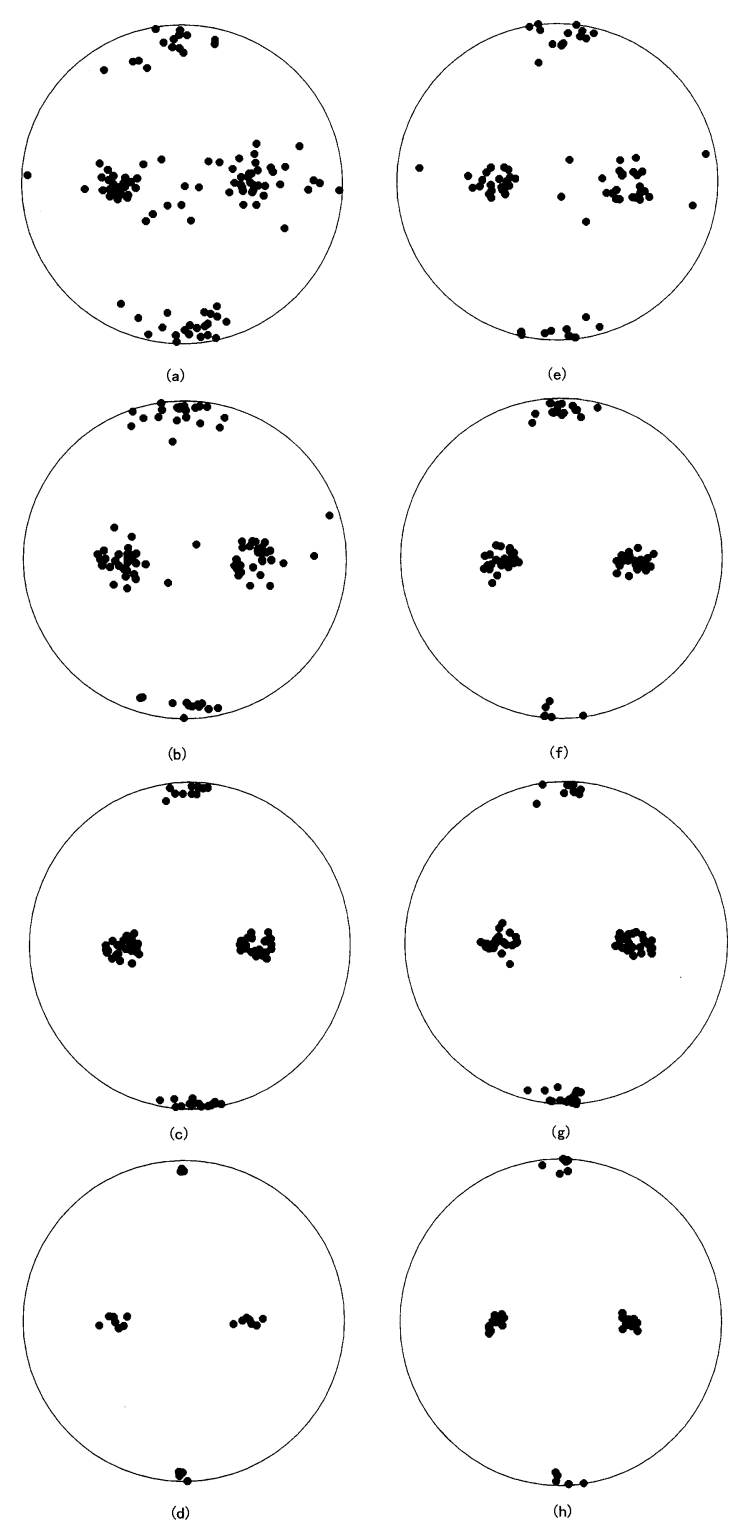

Fig. 4. $\{100\}$ pole figures representing secondary recrystallized grains.

(a), (b), (c) and (d): Material A with grain size classification of $D \leqq 5 \mathrm{~mm}, D \leqq 10 \mathrm{~mm}, D \leqq 20 \mathrm{~mm}$ and $D>20 \mathrm{~mm}$. (e), (f), (g) and (h): Material B with grain size classification of $D \leqq 5 \mathrm{~mm}, D \leqq 10 \mathrm{~mm}, D \leqq 20 \mathrm{~mm}$ and $D>20 \mathrm{~mm}$.

entation)) of nucleus orientation $\mathrm{N}$ should be smaller than certain values $\left(P_{\mathrm{CN}} \Sigma 1_{\mathrm{cr}}\right)$.

(b) $I_{\mathrm{N}}$ should be larger than certain critical values $\left(I_{\mathrm{Ncr}}\right)$.

(c) Nucleus orientation $\mathrm{N}$ should have a higher probabili-

ty of coming in contact with mobile grain boundaries than other orientation.

On the other hand, as it was reported that the nucleus of secondary recrystallization nucleates at the depth of $20-25 \%{ }^{1)}$ in case of the inherent inhibitor method, the data at the surface layer (1/5th thickness) are employed at first.

Figure 5 shows three dimensional orientation distributions of primary recrysatallization texture at surface layer, and is characterized by the intensities of $\gamma$-fiber in bcc and near $\{411\}\langle 148\rangle$, which contain $\Sigma 9$ coincidence orientations of Goss, i.e., as cold rolling reduction increases, the intensities of $\{111\}\langle 112\rangle$ and $\{411\}\langle 148\rangle$, which are the major $\Sigma 9$ coincidence orientations of Goss, increase. By the way, it was reported, in case of Goss secondary recrystal-
Table 4(a). Intensity of Goss $(\{110\}\langle 001\rangle)$ and $\{411\}\langle 122\rangle$ in the primary textures at the surface layer.

\begin{tabular}{|c|c|c|c|c|}
\hline Material & \multicolumn{2}{|c|}{ A } & \multicolumn{2}{c|}{ B } \\
\hline Reduction & $\{110\}\langle 001\rangle$ & $\{411\}\langle 122\rangle$ & $\{110\}\langle 001\rangle$ & $\{411\}\langle 122\rangle$ \\
\hline $81.4 \%$ & 0.701 & 1.026 & 0.454 & 1.159 \\
\hline 84.8 & 0.483 & 0.233 & 0.342 & 0.463 \\
\hline 87.6 & 0.271 & 0.219 & 0.290 & 0.273 \\
\hline $91.3(91.7)$ & 0.303 & 0.224 & 0.270 & 0.140 \\
\hline
\end{tabular}

Table 4(b). Intensity of Goss $(\{110\}\langle 001\rangle)$ and $\{411\}\langle 122\rangle$ in the primary textures at the central layer.

\begin{tabular}{|c|c|c|c|c|}
\hline Material & \multicolumn{2}{|c|}{ A } & \multicolumn{2}{c|}{ B } \\
\hline Reduction & $\{110\}\langle 001\rangle$ & $\{411\}\langle 122\rangle$ & $\{110\}\langle 001\rangle$ & $\{411\}\langle 122\rangle$ \\
\hline $81.4 \%$ & 0.659 & 0.280 & 0.442 & 0.273 \\
\hline 84.8 & 0.376 & 0.260 & 0.561 & 0.213 \\
\hline 87.6 & 0.447 & 0.341 & 0.338 & 0.181 \\
\hline $91.3(91.7)$ & 0.477 & 0.360 & 0.264 & 0.110 \\
\hline
\end{tabular}

lization, $\Sigma 9$ coincidence boundary is significant. ${ }^{21)}$ Figure 1(b) shows this quantitative relationship between Ic $\Sigma 9$ of Goss orientation and B8 (T), i.e., as the Ic $\Sigma 9$ of Goss texture is high, $\mathrm{B} 8$ is high.

Figure 6 shows intensity distributions of $I c \Sigma 9$ in primary recrysatallized specimens at surface layer and are characterized by $I c \Sigma 9$ of Goss and $\{411\}\langle 122\rangle$. In fact, the relation between Goss and $\{411\}\langle 122\rangle$ orientation is $\Sigma 3$ coincidence orientation relation mutually, and $\Sigma 9$ coincidence orientations for Goss and $\{411\}\langle 122\rangle$ are common. Therefore, in this case, not only Goss grain but also $\{411\}\langle 122\rangle$ could secondary-recrystallize due to the above-mentioned condition (c). However only Goss grains and dispersed Goss $(\{110\}\langle 227\rangle)$ have secondary-recrystallized, as already shown in Fig. 2. In addition, Table 4 shows the intensities $\left(I_{\mathrm{N}}\right)$ of Goss and $\{411\}\langle 122\rangle$ at both the surface and central layers quantitatively. The $I_{\mathrm{N}}$ of $\{411\}\langle 122\rangle$ are generally weak compared with one of Goss considering both the layers, i.e., due to the above-mentioned condition (b), this $\{411\}\langle 122\rangle$ might not secondary-recrystallize, even if $I c \Sigma 9$ was very high. This can be explained by the condition of Harase's proposal.

However, the B8-value difference in Fig. 1(b) between two materials (A, B), which mainly consists of the ratio of dispersed Goss grains in secondary recrystallized grains as shown in Fig. 2 and Fig. 4, cannot be explained yet. The reasons of this difference might be due to various possibilities. But all possibilities should be strongly connected with the primary textures because the quantity of the injected nitrogen (inhibitor intensity) and primary grain sizes (driving force) are the same. The relation between B8 values and other textural parameters have been investigated, expanding to the texture at the central layer.

As a result, two reasons may be proposed, one is the intensity of $\{411\}\langle 148\rangle$ (one of two major orientations of $\Sigma 9$ coincidence orientations for Goss) at the surface layer, and another is the Ic $\Sigma 5$ of dispersed Goss $(\{110\}\langle 227\rangle)$ at the central layer.

Concerning the former reason, the deviation of $\{411\}\langle 148\rangle$ is shaper than one of $\{111\}\langle 112\rangle(\fallingdotseq\{778\}$ $\langle 447\rangle)$ around the normal direction axis. As the result, as $\{411\}\langle 148\rangle$ is stronger, the sharpness of Goss texture is enhanced. ${ }^{17,22,23)}$ Figure 7 shows the relation between the in- 


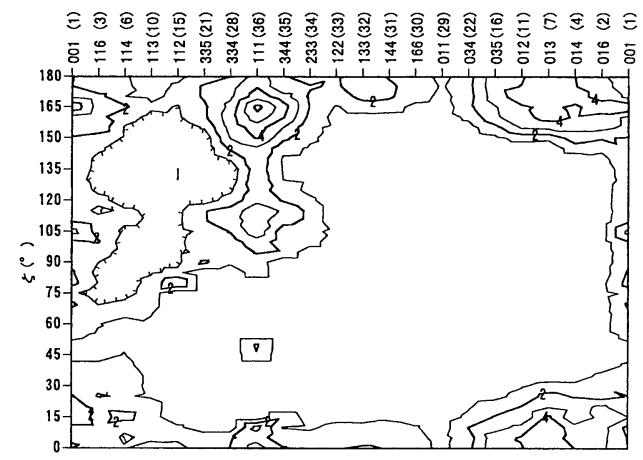

(a)

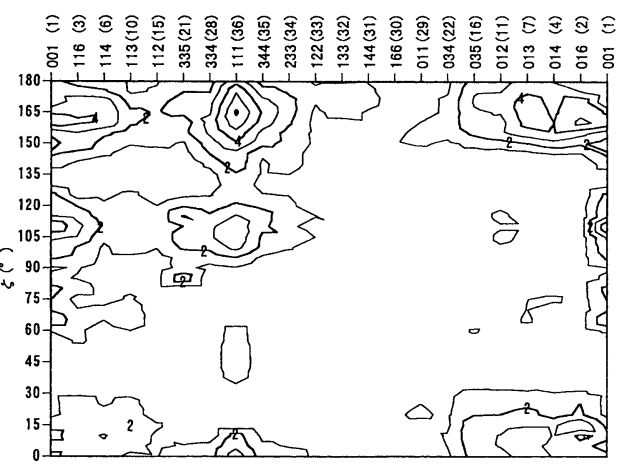

(b)

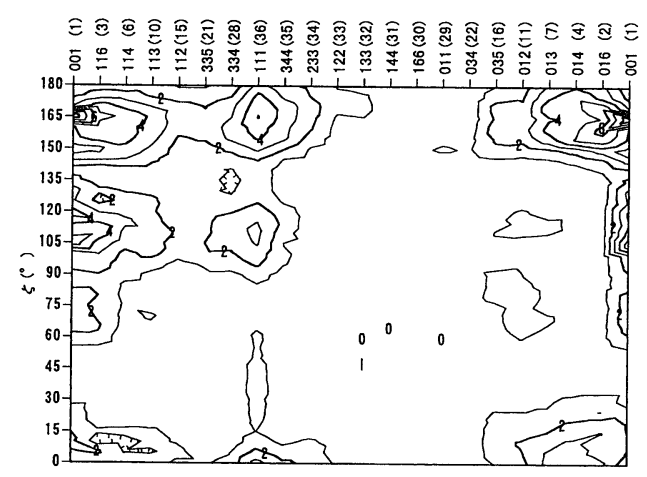

(c)

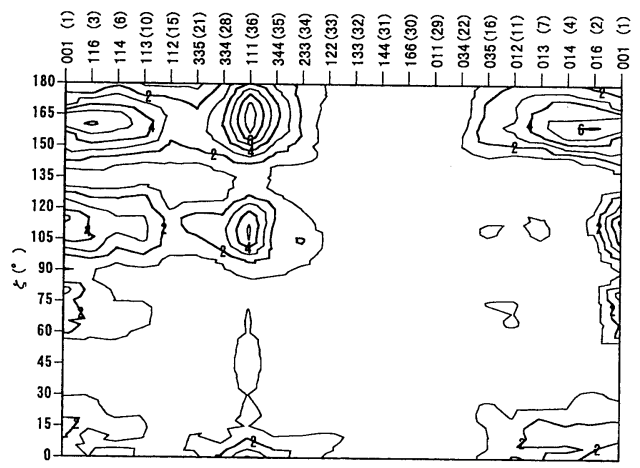

(d)

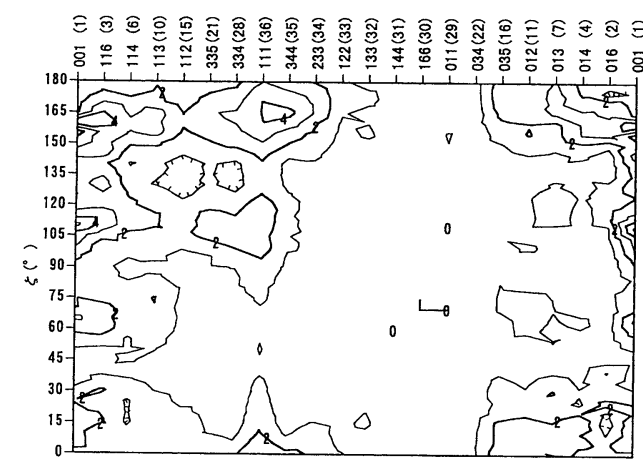

(e)

こ 응

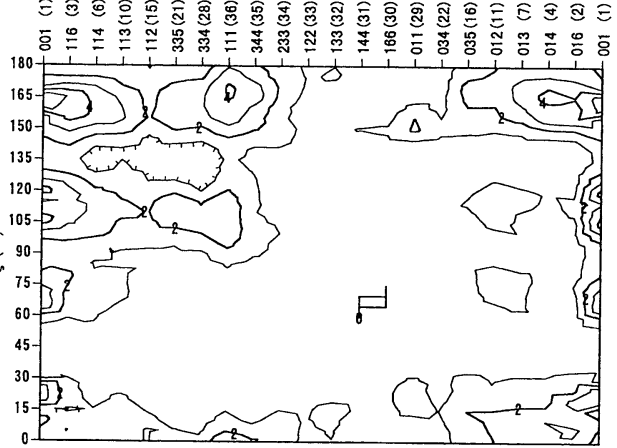

$(f)$

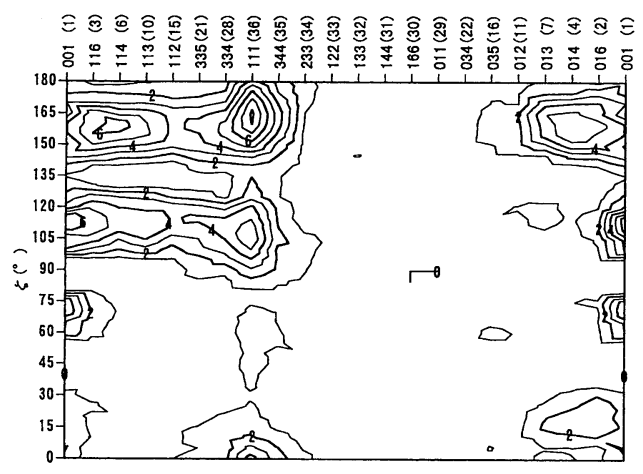

$(g)$

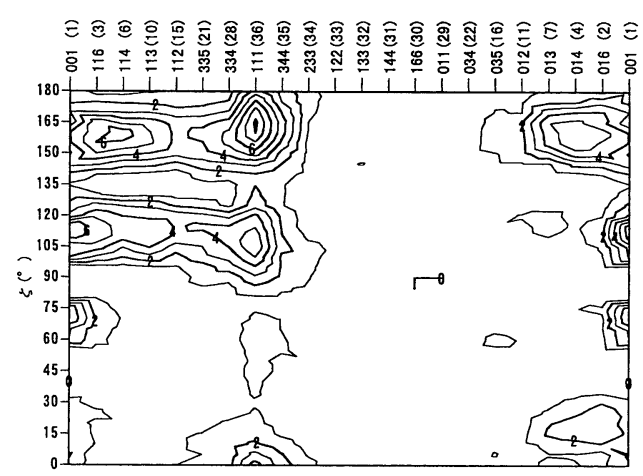

(h)

Fig. 5. Three dimensional orientation distributions of primary recrystallization texture (x random) at surface layer. (a), (b), (c) and (d): Material A with cold rolling reductions of 81.4, 84.8,87.6 and 91.3\%. (e), (f), (g) and (h): Material B with cold rolling reductions of $81.4,84.8,87.6$ and $91.7 \%$.

tensity of $\{411\}\langle 148\rangle$ and B8 and may explain this difference considerably seemingly. But as Goss grain grows at the expense of $\Sigma 9$ coincidence grains, the textural feature of eroded grains ( $\Sigma 9$ coincidence grains of Goss orientaion) could not be inherited. The reason has not been clarified yet.
Figure 8 shows intensity distributions of $I c \Sigma 5$ in primary recrystallized specimens at surface layer and is characterized by the intensity of dispersed Goss orientation $(\{110\}\langle 227\rangle)$. In addition, Fig. 9 shows the quantitative relation between cold rolling reduction and the intensity of dispersed Goss orientation in primary recrystallization tex- 


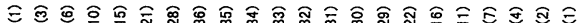

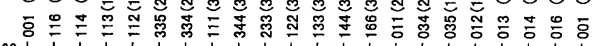

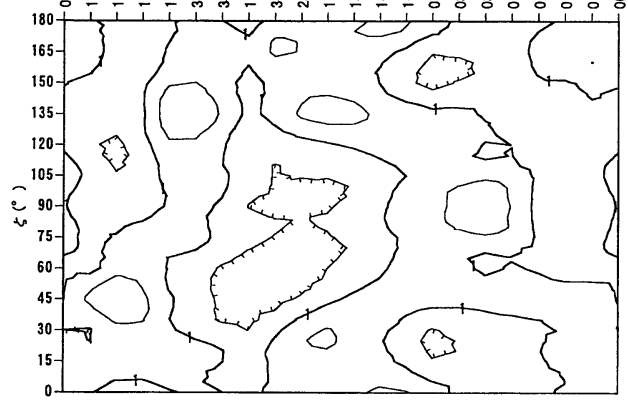

(a)

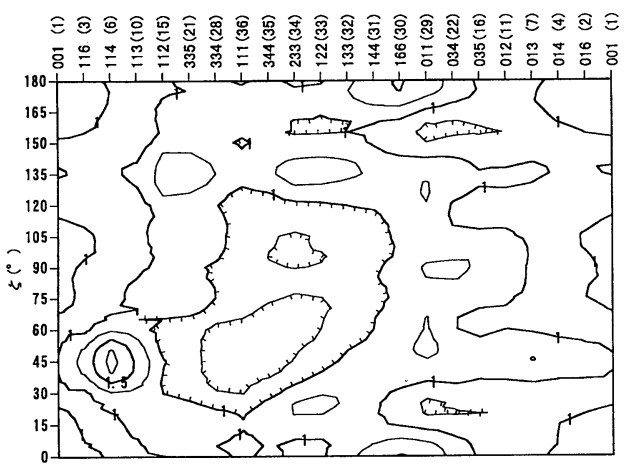

(b)

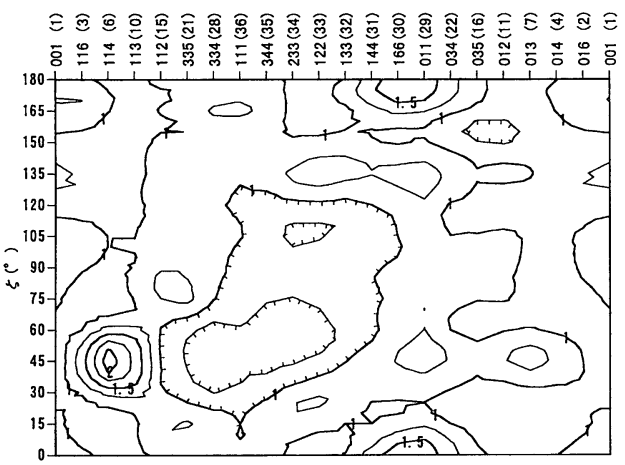

(c)

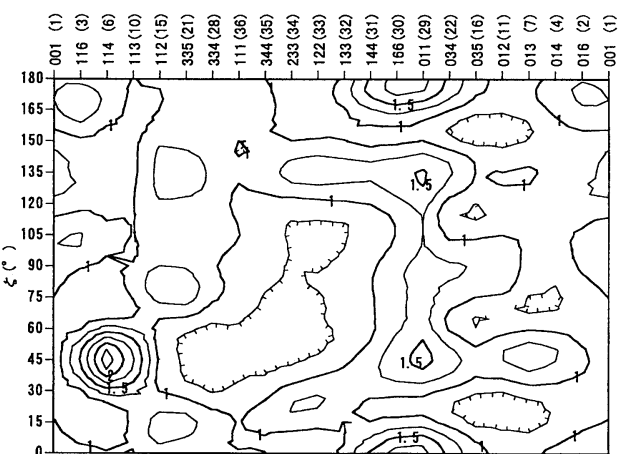

(d)
ลิ

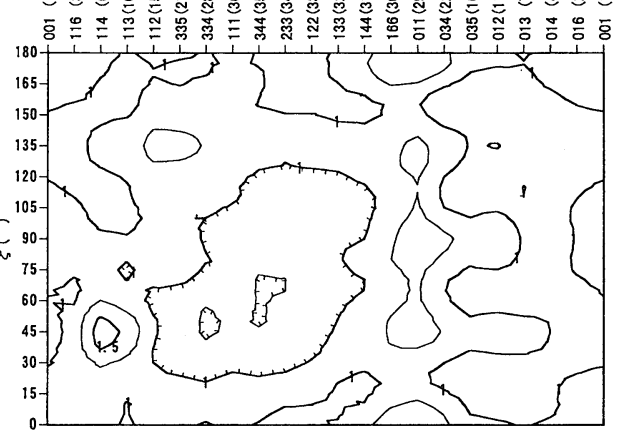

(e)

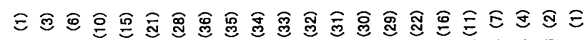

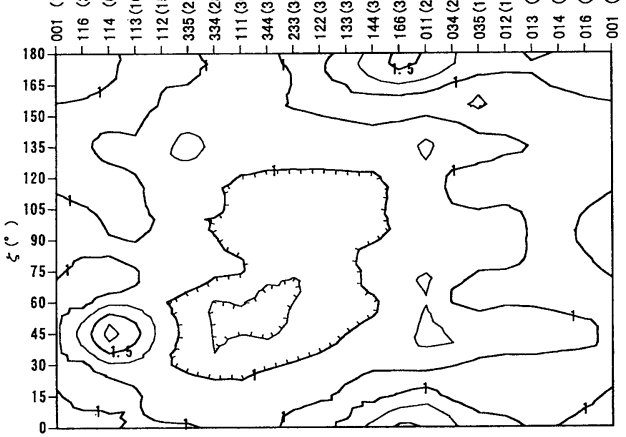

(f)

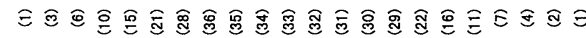

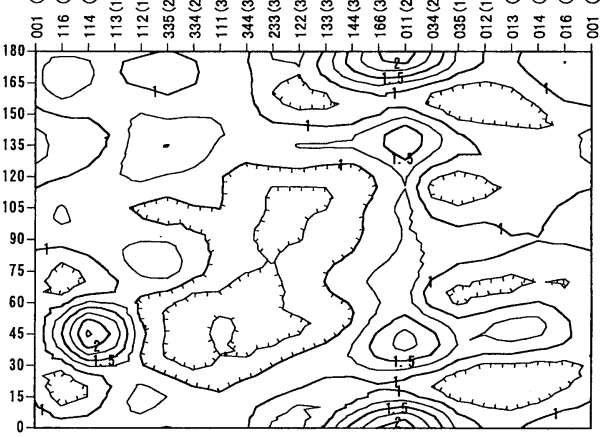

(g)

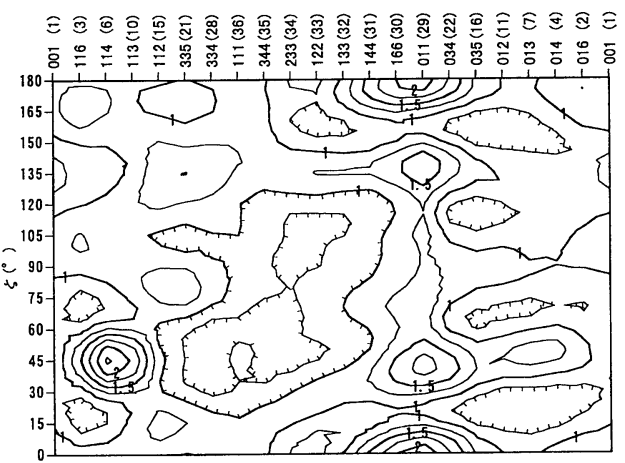

(h)

Fig. 6. Intensity distributions of $I_{c} \Sigma 9$ in primary recrystallized specimens at surface layer. (a), (b), (c) and (d): Material A with cold rolling reductions of 81.4, 84.8, 87.6 and 91.3\%. (e), (f), (g) and (h): Material B with cold rolling reductions of 81.4, 84.8, 87.6 and $91.7 \%$.

ture, and at the central layer the difference between material $\mathrm{A}$ and $\mathrm{B}$ can be found. Therefore, noticing the intensity of dispersed Goss orientation at the central layer, the latter reason is examined. Figure $\mathbf{1 0}$ shows the relation between B8 and the intensities of dispersed Goss orientation. At the surface layer (a), the difference between the relations still exits. However, as at the central layer (b) the considerably good correspondence of the relation for material A and B could be found, the texture not only at the surface layer but also at the other portion should be taken into account.

By the way, as the nuclei of secondary recrystallizarion of grain oriented silicon steel nucleate at the portion where 


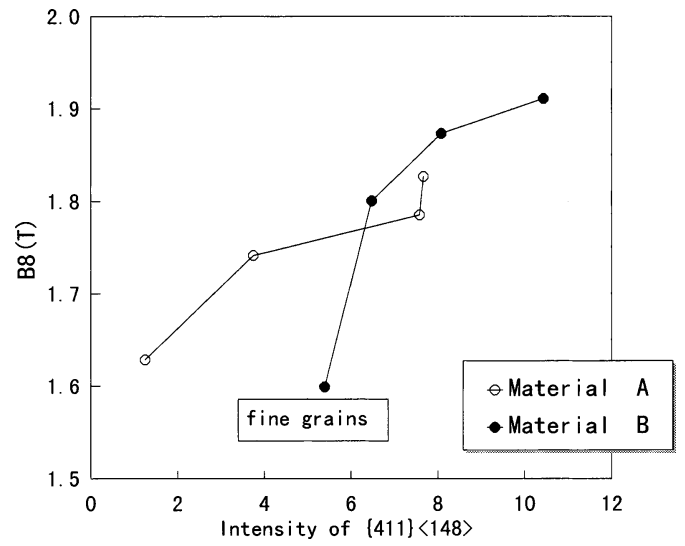

Fig. 7. Relation between intensity of $\{411\}\langle 148\rangle$ and B8.

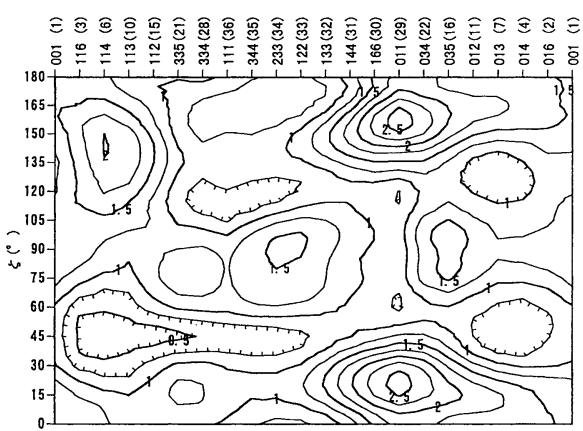

(a)

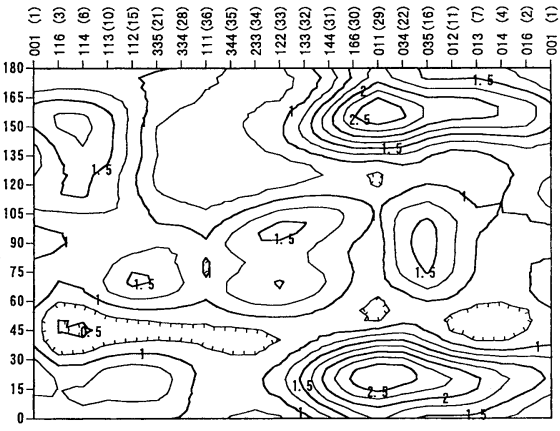

(b)

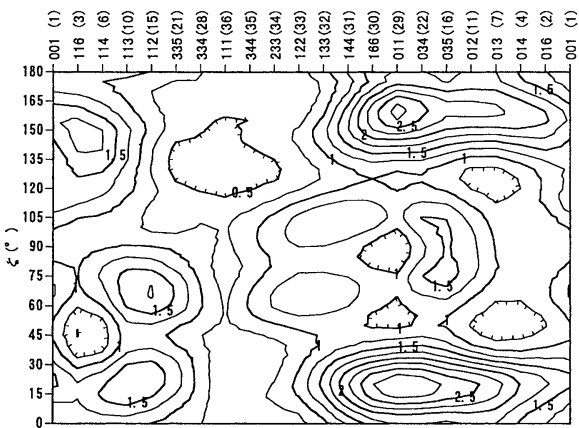

(c)

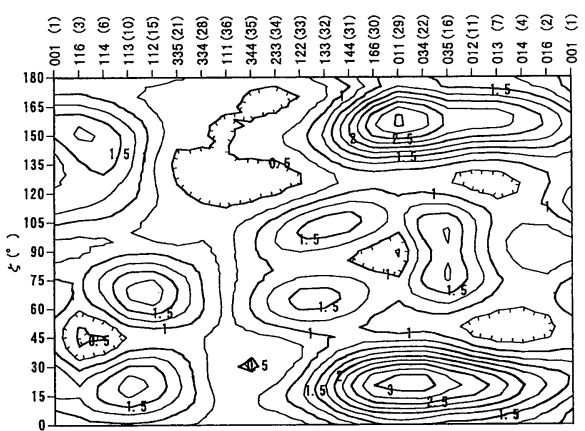

(d)

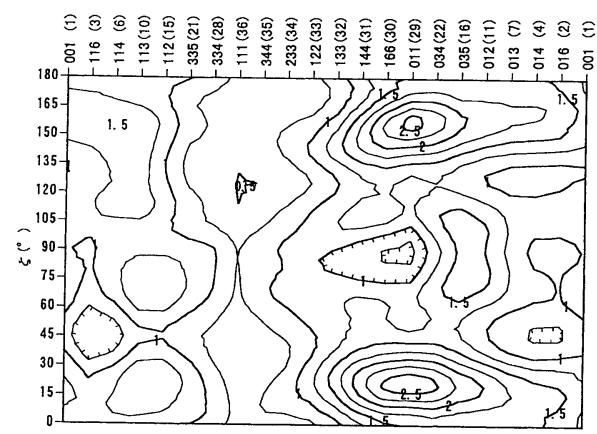

(e)

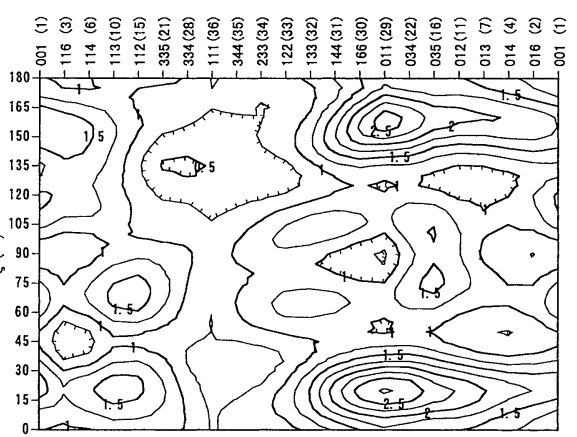

( $f$ )

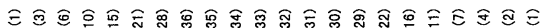

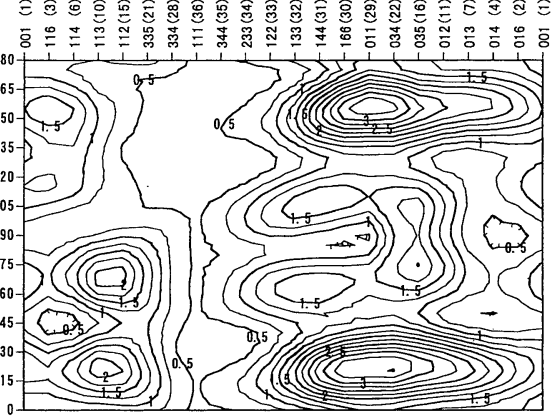

(g)

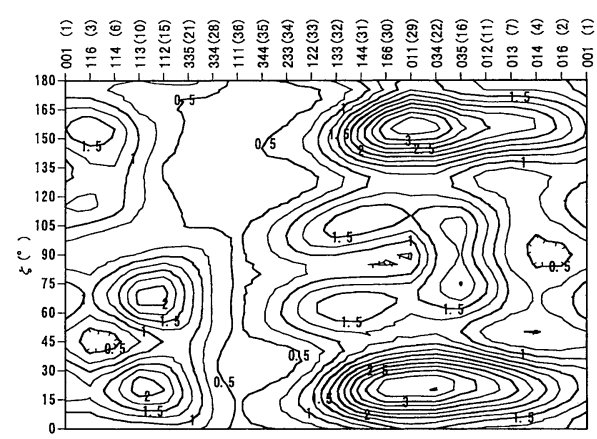

(h)

Fig. 8. Intensity distributions of Ic $\Sigma 5$ in primary recrystallized specimen at surface layer.

(a), (b), (c) and (d): Material A with cold rolling reductions of 81.4 , $84.8,87.6$ and $91.3 \%$. (e), (f), (g) and (h): Material B with cold rolling reductions of 81.4 , $84.8,87.6$ and $91.7 \%$. 


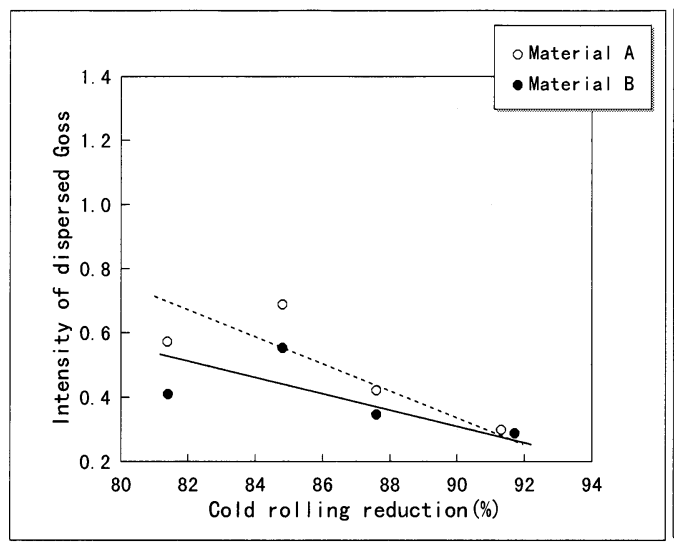

(a)

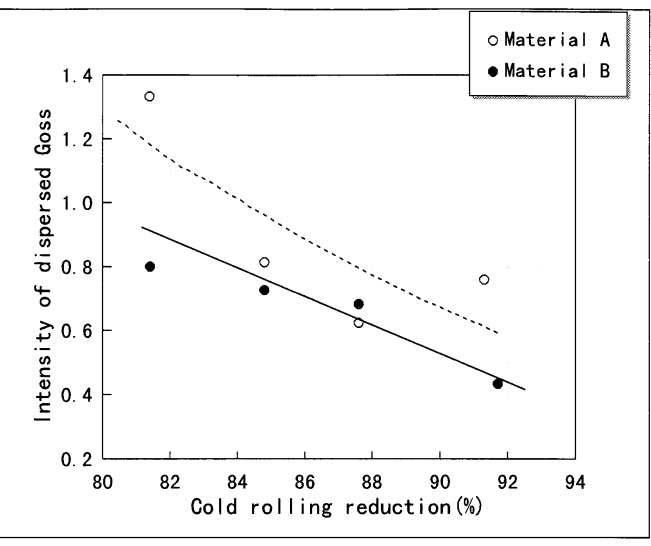

(b)

Fig. 9. Relation between cold rolling reduction and intensity of dispersed Goss

(a): at surface layer

(b): at central layer

(Dispersed Goss means $\{661\}\langle 126\rangle$ )

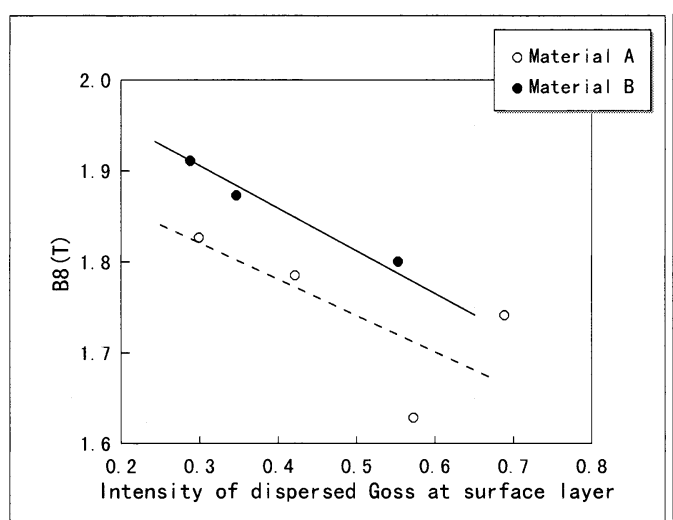

(a)

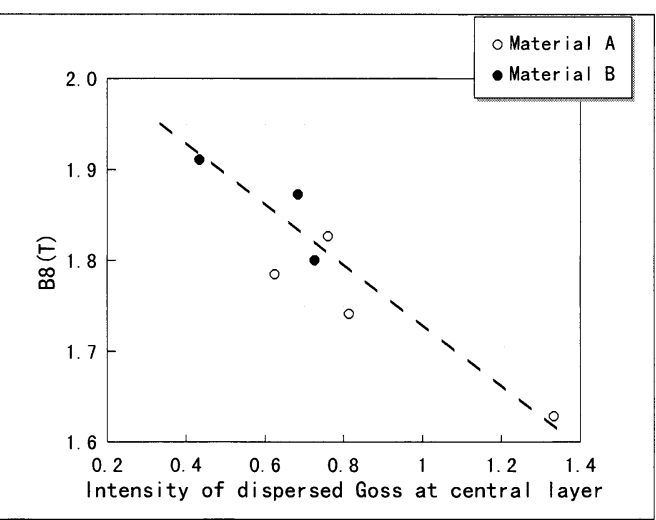

(b)

Fig. 10. Relation between intensity of dispersed Goss and B8. (a): at surface layer. (b): at central layer and B8.

Table 5. Intensities of $I c \Sigma 5$ and $I c \Sigma 9$ of Goss and dispersed Goss $(\{661\}\langle 126\rangle)$.

\begin{tabular}{|c|c|c|c|c|c|c|c|c|}
\hline Positions & \multicolumn{4}{|c|}{ Surface layer } & \multicolumn{4}{c|}{ Central layer } \\
\hline Ic $\Sigma$ & \multicolumn{2}{|c|}{ Ic $\Sigma 5$} & \multicolumn{2}{|c|}{ Ic $\Sigma 9$} & \multicolumn{2}{|c|}{ Ic $\Sigma 5$} & \multicolumn{2}{|c|}{ Ic $\Sigma 9$} \\
\hline Materials & $\mathrm{A}(81.4 \%)$ & $\mathrm{B}(91.6 \%)$ & $\mathrm{A}(81.4 \%)$ & $\mathrm{B}(91.6 \%)$ & $\mathrm{A}(81.4 \%)$ & $\mathrm{B}(91.6 \%)$ & $\mathrm{A}(81.4 \%)$ & $\mathrm{B}(91.6 \%)$ \\
\hline Goss & 1.595 & 1.873 & 1.156 & 2.163 & 1.466 & 1.355 & 1.339 & 1.998 \\
\hline Dispersed Goss & 2.267 & 3.084 & 0.896 & 1.049 & 1.805 & 2.916 & 1.041 & 0.940 \\
\hline
\end{tabular}

the intensity of the inhibitor substances, such as AlN, MnS and so on, deteriorates below a certain level, the dissolution and diffusion of inhibitor substances function as an important role. Therefore, if the secondary recrystallization temperature is high, this dissolution and diffusion happen in an instant. In fact, in case of the acquired inhibitor method, as the average of primary grain diameter is rather large $(\fallingdotseq 23$ $\mu \mathrm{m})$, the temperature of secondary recrystallization is higher than inherent inhibitor method. ${ }^{24)}$ In addition, the interval between the start and the end of secondary recrystallziation is shorter compared with the inherent inhibitor method. ${ }^{1,25,26)}$ Accordingly, in case of the acquired inhibitor method, the viable nuclei of secondary recrystallization will nucleate not only at the surface layer but also at other portions of the sheets compared with the inherent inhibitor methods, i.e., the orientation of viable secondary nuclei will depend on the texture of other portions besides the surface layer.

The detailed analysis by using textures through the thickness should be carried out hereafter.

\subsection{The Velocity of $\Sigma 5$ and $\Sigma 9$ Coincidence Bound- aries}

Concerning the velocity of grain growth, Nakayama et al. proposed the grain growth equation, ${ }^{27}$

$$
d R / d t=A M E(1 / R c-K / R-K Z / A),
$$

$R=$ radius of secondary grain, $A=$ form factor, $M=$ mobility of a grain boundary, $E=$ grain boundary energy, $R_{\mathrm{c}}=$ critical radius of primary grains, $K=$ ratio of secondary grain boundary energy to primary grain boundary energy, $Z=$ Zener term. 


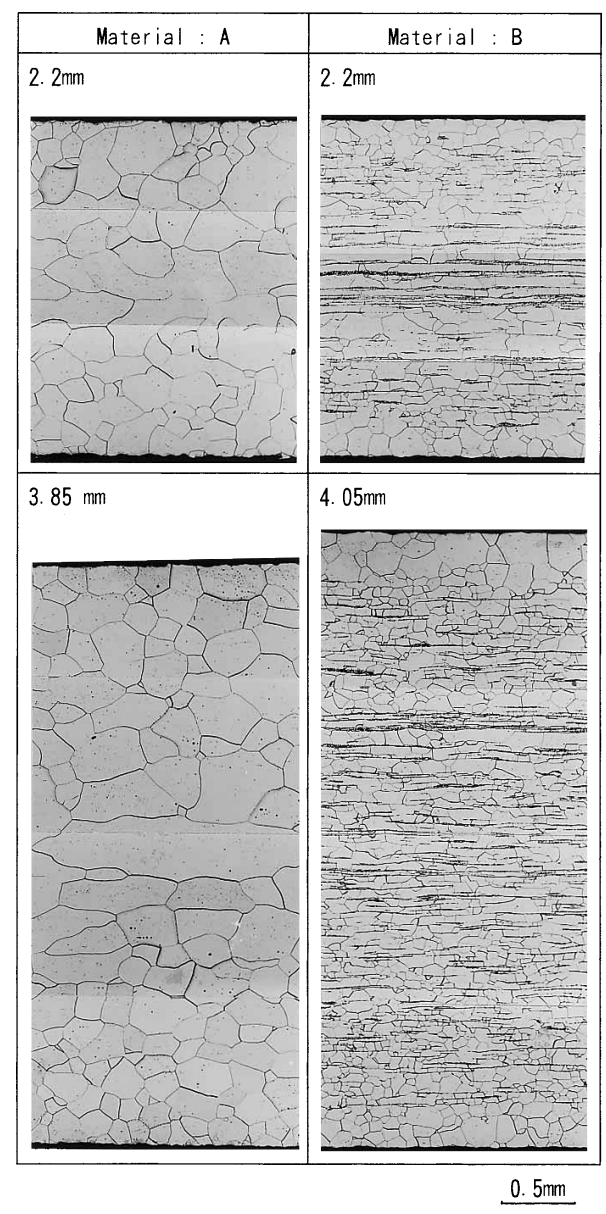

Fig. 11. Microstructures before cold rolling.

The total driving force consists of three components: the driving force derived from the grain boundary energy of primary grains, the retarding force from the shrinking force of the secondary grain, and the retarding force by the pinning effect of second phase particles.

Nakajima et al. investigated the grain boundary migration on coincidence grain boundary. ${ }^{28,29)}$ On the other hand, Yoshitomi et $a l .{ }^{26)}$ proposed, by comparing the mobility (M) of $\Sigma 9$ and $\Sigma 5$ coincedence boundary, that the relative mobility might depend on the temperature, and at high temperature $\mathrm{M} \Sigma 9$ (mobility of $\Sigma 9$ coincidence grain boundary) would be as same as $\mathrm{M} \Sigma 5$.

Table 5 shows $I c \Sigma 5$ and Ic $\Sigma 9$ of Goss and dispersed Goss orientation. Although Ic $\Sigma 5$ of dispersed Goss of material B $(91.6 \%)$ is highest, the secondary texture of dispersed Goss is very weak, and the size of sharp Goss secondary grains is larger than dispersed Goss as shown in Fig. 4. Therefore, the $\Sigma 9$ coincidence boundary can move much faster than $\Sigma 5$ coincidence boundary in this case.

Therefore, if $M \Sigma 9$ would be as same as $M \Sigma 5$, the difference of velocity might be caused by the grain boundary energy. ${ }^{27)}$ Because in this study, $Z$ and $R c$ in the above equation were controlled as same. In addition, at this high temperature (around $1323 \mathrm{~K}$ ), as the mobility means physically the "self-diffusion coefficient", $\mathrm{M}_{9} \doteqdot \mathrm{M}_{5}$ and the reason of the velocity difference might depend on the energy for each coincidence grain boundary. The coincidence grain boundary is special in the grain boundary energy, ${ }^{30)}$ especially $\Sigma 9$ coincidence grain boundary in the grain oriented silicon

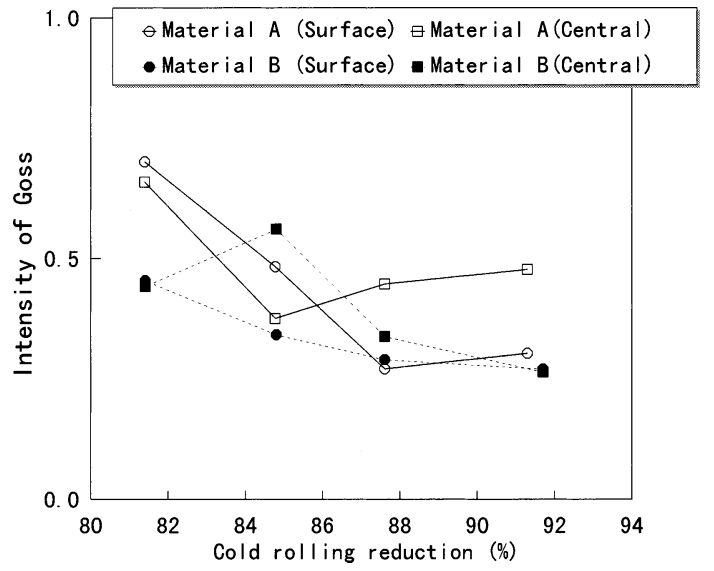

Fig. 12. Relation between cold rolling reduction and intensity of Goss.

steel. ${ }^{31-34)}$ In conclusion, the energy of $\Sigma 9$ coincidence boundary might be much lower than that of $\Sigma 5$.

\subsection{Primary Recrystallization Texture Formation}

Thus far, the relationship between primary and secondary texture has been discussed. In this section, the primary texture formation is discussed briefly. Primary textures depend on various metallurgical parameters, i.e., chemical compositions, ${ }^{35)}$ texture $^{36)}$ and grain size ${ }^{37)}$ before cold rolling, heat treatment before cold-rolling, ${ }^{38,39)}$ roll diameter of cold rolling mill, ${ }^{40)}$ temperature of cold rolling operation, ${ }^{36)}$ cold rolling reduction, ${ }^{37,42)}$ heating rate of annealing ${ }^{43)}$ and so on. These parameters are related mutually.

Figure 11 shows the microstructure before cold rolling. Material A has coarse grains because of no $\alpha-\gamma$ transformation. This causes rather strong $\{110\}$, a little strong $\{100\}$ and a little weak $\{111\}^{37)}$ in primary texture.

Figure 12 shows the intensity of Goss orientation in the primary texture. Lager grain size before cold rolling causes it stronger and higher cold rolling reduction causes it weaker. This is well-known in the field of primary recrystallization on flat steel products. ${ }^{37)}$ Furthermore, in order to investigate the primary texture of grain oriented silicon steel, many studies have been carried out and reported by changing parameters such as cold-rolling temperature. ${ }^{41)}$ But this kind of three dimensional analysis using such as Vector method has been very seldom. ${ }^{44)}$

In this study, it becomes clarified that the cold rolling reduction gives the similar effect to primary texture as that of $\mathrm{C}$ content. The increase of $\mathrm{C}$ content causes the grain size before cold rolling smaller. Therefore Ic $\Sigma 9$ of Goss orientation (mainly $\{111\}\langle 112\rangle \fallingdotseq\{778\}\langle 447\rangle$ ) increases as shown in Fig. 5 and Table 5, although the intensity of Goss orientation decreases as shown in Fig. 12. In addition, as cold rolling reduction increases, near $\{411\}\langle 148\rangle$ (connected with $\alpha$-fiber in bcc) also develops and Goss orientation decreases. As a result, because the preferable textural conditions are obtained, secondary recrystallized Goss orientation becomes sharper and its grain size becomes larger. But, in case of too high cold rolling reductions, ${ }^{16)}$ Goss grains do not secondary-recrystallize any more because of small quantity of Goss nuclei in the primary texture according to Harase's condition $(b)^{21)}$.

It will be summarized that the increases of $\mathrm{C}$ content and 
cold rolling reduction enhance the Ic $\Sigma 9$ of Goss orientation, and secondary recrystallized Goss grains becomes sharper until the lower limit of the intensity of Goss orientation.

The preferable primary texture has become clear in case of acquired inhibitor method of grain oriented silicon steel. Hereafter the way of the formation of primary texture should be examined and the mechanism should be investigated with the aid of other steel products, e.g., mild steel, ${ }^{45}$ ) stainless steel and non-oriented electrical steel. ${ }^{36}$ )

In addition, in case of the acquired inhibitor method of grain oriented silicon steel, as the primary texture, inhibitor condition and primary structure can be given separately, this kind of study can be easily carried out.

\section{Conclusions}

In order to investigate the relationship between primary and secondary recrystallization texture of grain oriented silicon steel, the specimens with various kinds of the primary texture were obtained by changing the cold rolling reduction and carbon content, and were secondary-recrystallized by the acquired inhibitor method. Furthermore in order to avoid the influence of inhibitor and estimate the pure effect of texture, the same final thickness was applied.

(1) For primary texture formation, $\mathrm{C}$ content and cold rolling reduction will function similarly, i.e., their increases will enhance the Ic $\Sigma 9$ of Goss orientation.

(2) The sharpness of Goss texture in the secondary recrystallization will depend mainly on the Ic $\Sigma 9$ of Goss orientation and partially on the texture besides other portions of the surface layer in the primary texture.

(3) Deviation from Goss orientation will be caused of the secondary recrystallized dispersed Goss orientation.

(4) $\Sigma 9$ coincidence boundary will move much faster than $\Sigma 5$ boundary. The reason might be that the grain boundary energy of $\Sigma 9$ will be much lower than that of $\Sigma 5$.

\section{REFERENCES}

1) M. Matsuo: ISIJ Int., 29 (1989), No. 10, 809.

2) N.Takahashi and J. Harase: Mater. Sci. Forum, 204-206 (1996), 143.

3) N. P. Goss: U.S. Patent 1965 559, (1934).

4) M. F. Littmann and J. E. Heek: U. S. Patent 2599 340, (1952).

5) M. F. Littmann, J. Appl. Phys., 38 (1967), 1104.

6) S. Taguchi: Trans. Iron Steel Inst Jpn., 17 (1977) 604.

7) S. Taguchi and A. Sakakura: U.S. Patent 3159 511, (1964).

8) S. Taguchi, A. Sakakura and H. Tashima: U.S. Patent 3287183 , (1966)

9) A. Sakura, S. Taguchi, T. Wada, K. Ueno, T. Yamamoto and N. Urushiyama: U.S. Patent 3636 579, (1972).

10) T. Imanaka, T. Kan, Y. Obata and T. Sato: Japanese Patent Publication S49-61019, (1974).

11) I. Goto, I. Matoba, T. Imanaka T. Goto and T. Kan: 2nd Conf. Proc. of Soft. Magnetic Materials, Vol. 2, European Physical Society, Cardiff, (1975), 262.

12) Y. Suga, F. Matsumoto and T. Nakayama: Japanese Patent,
Application No. S57-165066, (1982).

13) N. Takahashi, Y. Suga and H. Kobayashi: J. Magn. Magn. Mater. 160 (1996) 98.

14) Y. Ushigami, T. Nakayama, Y. Suga and N. Takahashi: Mater. Sci. Forum, 204-206 (1996), 599.

15) Y. Ushigami, T. Nakayama, Y. Suga and N. Takahashi: Mater. Sci. Forum, 204-206 (1996), 605.

16) S. Arai, Y. Ushigami and N. Takahashi: Mater. Sci. Forum, 204-206 (1996), 617.

17) Y. Ushigami T. Kubota and K. Murakami: Proc. of the 12th Int. Conf. on Textures of Materials (ICOTOM-12), ed. by J. A. Szpunar, National Research Council, Canada, (1999), 981.

18) D. Ruer and R. Baro: J. Appl. Crystallogr., 10 (1977), 458.

19) R. Shimizu, J. Harase and D. J. Dingley: Acta Metal. Mater., 38, (1990) No. 6, 973.

20) T. Nozawa, T. Yamamoto, Y. Matuso and Y. Ohya: IEEI TRANSACTION ON MAGNETICS, VOL. MAG-14, (1978) NO. 4, 252.

21) J. Harase, R. Shimizu, J. Kim and J. S. Woo: Proc. of the 12th Int. Conf. on Texture of Materials (ICOTOM-12), ed. by J. A. Szpunar, National Research Council, Canada, (1999), 1009.

22) Y. Ushigami and K. Kuroki: Japanese Patent Application No. H863146, (1996).

23) Y. Ushigami and K. Kuroki: Japanese Patent Application No. H8132560, (1996).

24) N. Fujii, Y. Ushigami and T. Kubota: CAMP-ISIJ, 9 (1996), 444.

25) Y. Ushigami, T. Nakayama, Y. Suga and N. Takahashi: Mater. Sci. Forum, 204-206 (1996), 599.

26) Y. Yoshitomi, Y. Ushigami, N. Takahashi, T. Nakayama, Y. Suga and J. Harase: Mater. Sci. Forum, 204-206 (1996) 629.

27) Y. Ushigami and T. Nakayama: Mater. Sci. Forum, 157 (1994), 1081.

28) H. Nakajima, T. Ueda, S. Tsurekawa, K. Ichikawa and H. Yoshinaga: Tetsu-to-Hagané, 82 (1996), No. 3, 238.

29) M. Uehara and H. Toshida and H. Nakajiman: Tetsu-to-Hagané, 84 (1998), No. 3, 212.

30) G. C. Hasson and C. Goux: Scr. Metall., 5 (1971), 889.

31) M. Shiozaki, I. Matoba, T. Kan and T. Gotoh: Trans. JIM, 19 (1978), 85 .

32) J. Harase, R. Shimizu and T. Watanabe: Proc. 7th RISO Int. Symp. on Met. Mater. Sci., ed. by N. Hansen, D. J. Jensen, T. Leffers and B. Ralph, Risø Nat. Lab., Roskilde, (1986) 343.

33) Y. Ushigami, Y. Suga, N. Takahashi, K. Kawasaki, Y. Chikaura and H. Kii: J. Mater. Eng., 13 (1991), 113.

34) B. Hutchinson and H. Homma: Proc. 3rd Int. Conf. of Grain Growth, ed. by H. Weiland, B. L. Adams and A. D. Rollett, TMS, Warrendale, PA, (1998), 1104.

35) T. Kubota, K. Kuroki, Y. Matsuo and N. Takahashi.: Mater. Sci. Forum, 204-206 (1996), 539.

36) T. Kumano, T. Kubota and N. Takahashi: J. Mater. Eng. Performance, 4, (1995) No.4, 401.

37) M. Matsuo and S. Hayashi and S. Nagashima: Adv. X-Ray Anal., 14 (1971), 214.

38) M. Komatsubara, Y. Hayakawa, T. Takamiya, M. Muraki, C. Maeda, M. Ishida and N. Morito: J. Phys. IV France, 8 (1998), 467.

39) M. Matsuo, T. Sakai, M. Tanino, T. Shindo and S. Hayami: Proc. 6th Int. Conf. on Texture of Materials, ISIJ, Tokyo, (1981), 918.

40) S. Hashimoto, T. Yakushiji and Y. Maeda: Tetus-to-Hagané, 76 (1990), No. 1, 50.

41) M. Tanino, M. Matsuo, T. Shindo, T. Sakai and F. Matsumoto: Proc. 6th Int. Conf. on Texture of Materials, ISIJ, Tokyo, (1981), 928.

42) K. Takashima, T. Sato and F. Matsumoto: AIP Conf. Proc., No. 29 Magnetism and Magnetic Materials, Philadelphia, (1975), 566.

43) J. W. Shoem and D. E. Margerum: U.S. Patent 4898 626, (1990).

44) S. Mishra, C. Daemann and K. Luecke: Acta Metall., 32, (1984), No.12, 2185.

45) B. Hutchinson and E. Nes: Mater. Scie. Forum, 94-96 (1992), 385. 